\title{
Bacterial and mycotic factors in the pathogenesis of latent endometritis and salpingitis in cows and a decrease in the sanitary quality of milk
}

\author{
A.V. Filatova ${ }^{1, *}$, G.M. Firsov ${ }^{2}$, S.O. Loshchinin ${ }^{1}$, V.T. Akhmadov ${ }^{3}$, and N.S. Fayzulina ${ }^{2}$ \\ ${ }^{1}$ Saratov State Agrarian University named after N.I. Vavilov, Teatralnaya Ploshchad, 1, 410012, \\ Saratov, Russia \\ ${ }^{2}$ Volgograd State Agrarian University, Universitetskaya Str., 29, 400094, city of Volgograd, Russia \\ ${ }^{3}$ FSBEI HE Chechen State University, 32 Aslanbeka Sharipova Str., Grozny, 364093, Russia
}

\begin{abstract}
In $82 \%$ of cows, contamination of the genitals with conditionally pathogenic microflora of E. coli was established in $17 \%$ of cases, S. aureus - $15 \%$, P. mirabilis - $14 \%$, S. pyogenes - $14 \%$, S. pyogenes, R. vulgaris, C. albicans - $14.0 \%$; S. aureus, E. coli, C. albicans $14.0 \%$; S. aureus, P. mirabilis, E. coli, C. albicans, A. fumigatus, M. racemosus in $12 \%$ of cases of latent endometritis. In salpingitis, microorgans were isolated in the association of S. aureus, P. mirabilis, C. albicans in $28.5 \%$ of cases; E. coli, P. mirabilis in $27.7 \%$ of cases; E. coli, P. vulgaris, C. albicans, A. fumigatus $-25.2 \%$; S. aureus, E. coli, C. albicans, A. fumigatus $-13.1 \%$, the rest in $5.5 \%$ of cases. In patients with latent endometritis and salpingitis, fungi were isolated in $29.6 \%$ of cases of A. fumigatus and in $70.4 \%$ of cases - C. albicans and C. crusei. Milk obtained from sick cows with latent endometritis and salpingitis showed 2 times higher total bacterial contamination than milk obtained from healthy animals.
\end{abstract}

\section{Introduction}

After labor, a period of time is needed to restore the processes of endometrial regeneration and cyclic activity of the ovaries, before cows restore fertility [1]. Studies [3] have proved that bacterial infections that cause inflammation of the uterus in the form of latent endometritis and oviducts in the form of salpingitis are common in modern dairy cattle and lead to a decrease in productivity and subfertility. According to the presented data [6], the incidence of latent endometritis and salpingitis was $21 \%$. It is interesting, that according to publications [7], the hygiene of labor and the early postpartum period is the least important in most epizootic models that determine the risk factors for the development of dumplex uteri and salypengis inflammation in cows. Studies [8] indicate that endometrial pathogenic E. coli were detected from animals with uterine diseases, which, according to research

\footnotetext{
*Corresponding author: avdeenko0106@mail.ru
} 
materials [2], are associated with $T$. pyogenes and the severity of the course of inflammation of the endometrium and the mucous membrane of the oviducts, as well as clinical manifestations of uterine and oviduct diseases. Diseases of the uterus and oviducts according to the presented materials [9] are associated with the release of pathogenic bacteria, in particular E. coli, Trueperella pyogenes, Fusobacterium necrophorum, Prevotella and Bacteroides. Studies [4] have confirmed that T. pyogenes, F. necrophorum and Prevotella act synergistically, which makes it difficult to diagnose and treat latent endometritis and salpingitis. More recent experiments [11] using aerobic and anaerobic cultures confirm the importance of E. coli, T. pyogenes and anaerobic bacteria in inflammation of the uterus and oviducts in cows. There is data from studies [10] using fluorescent probes for bacteria and sequencing of $16 \mathrm{~S}$ ribosomal RNA genes that a sparse microbiome exists in the uterus and oviducts, even during pregnancy. The female cattle has a number of protective mechanisms against microbial contamination of the uterus and oviducts, which provide anatomical barriers to ascending infections, except during labor and insemination. The question of whether the resident flora of the vagina can also compete with pathogens to limit the disease is controversial [12]. Nevertheless, there are a number of antimicrobial peptides, glycoproteins and mucins in the vagina, cervix, uterus and oviducts that counteract bacterial contamination and inhibit the growth of bacteria.

The purpose of the study is to establish the role of bacterial and mycotic factors in the pathogenesis of latent inflammation of the uterus and oviducts in high-yielding cows and a decrease in the sanitary quality of milk.

\section{Materials and methods}

The experiments were carried out in various natural and economic regions of the Russian Federation. A total of 1,758 dairy cows were monitored - Holstein-Frisian, Black-andwhite, Simmental and Red Steppe in the period from 2015 to 2020. The diagnosis of latent endometritis and salpengitis was confirmed by a pathoanatomic protocol and histological examinations of the endometrial mucosa and oviducts, based on the materials presented in the publication $[4,5]$. Microbiological studies of sterile samples obtained from the uterine cavity and oviducts from 35 culled cows were carried out by inoculation for Endo, Koda and Saburo media. Using "Bergi's Brief Determinant of Bacteria" (1980) cit. according to [3], and the method of N.A. Spesivtseva (1964) cit. according to [4] for fungi, the species identity was determined and their identification was carried out. For this purpose, the plates "Diagnostic Systems", city of Nizhny Novgorod, were used, as well as microscopy by gram and cultural diagnostics were performed by the method of inoculation on wort - agar. The obtained digital data was processed using the "Statistics" program adapted for the "Pentium - 10" PC.

\section{Results and discussion}

After conducting a microbiological study of the obtained material from cows with symptoms of latent course of endometrial disease and oviducts, microorganisms were identified in the amount of 15 species and 1327 isolates. The data of a bacteriological study of secretions from the external cervix of sick cows are presented in Table 1.

Table 1. Results of bacteriological examination of the cervical secretions of cows.

\begin{tabular}{|c|c|c|}
\hline Indicators & Latent endometritis & Salpingitis \\
\hline $\begin{array}{c}\text { Number of microbial } \\
\text { cells, million in 1 ml }\end{array}$ & $4.275 \pm 12.46$ & $2.224 \pm 10.68$ \\
\hline Isolated cultures of & Streptococcus, Staphilococcus, & Streptococcus, \\
\hline
\end{tabular}




\begin{tabular}{|c|c|c|}
\hline microorganisms & Escherichia, Proteus, & Staphilococcus, \\
& Pseudomonas, Bacillus, & Escherichia, Bacillus, \\
& Enterobacter & Enterobacter \\
\hline
\end{tabular}

When studying samples of exudate obtained from animals with latent endometritis, $4,275 \pm 12.46$ million microbial cells were found in $1 \mathrm{ml}$, and 2,224 \pm 10.68 million microbial cells in $1 \mathrm{ml}$ were isolated from animals with salpingitis. The analysis of microbiological data showed that microorganisms in association with the predominance of $\mathrm{G}(-)$ rods were isolated more often with latent endometritis, which occurred in combination with salpingitis. Analysis of the investigated material showed that in the samples of the contents of the uterus and oviducts obtained from cows with latent endometritis and salpingitis bacteria and fungi in associative forms in $82 \%$ of cases often stand out, mainly such as $E$. coli in $17 \%$ of cases, S. aureus - $15 \%$, P. mirabilis - 14\%, S. pyogenes $-14 \%$, S. pyogenes, $P$. vulgaris, C. albicans - 14,0\%; S. aureus, E. coli, C. albicans is $14.0 \%$; S. aureus, $P$. mirabilis, E. coli, C. albicans, A. fumigatus, $M$. racemosus in $12 \%$ of cases of cow disease with latent endometritis. When the disease of cow salpingitis is allocated as the primary association of microorganisms $S$. aureus, P. mirabilis, C. albicans in $28.5 \%$ of cases; E. coli, P. mirabilis in $27.7 \%$ of cases; E. coli, P. vulgaris, C. albicans, A. fumigatus - 25.2\%; S. aureus, E. coli, C. albicans, A. fumigatus - 13,1\%, and other association of microorganisms and fungi in $5.5 \%$ of cases. Mycological studies and their analysis showed that microscopic fungi were isolated in animals with latent endometritis and salpingitis in $29.6 \%$ of cases - A. fumigatus and in $70.4 \%$ of cases - C. albicans and C. crusei. Microflora was isolated in monoculture in $12 \%$ of cows with latent endometritis and salpingitis. Studies have shown that bacteria can cause inflammatory process in female genitals, the proportion of cases in this case is $25 \ldots . .50 \%$ and fungi, this is in the range of $45 \ldots 80 \%$ of cases, from isolated microflora microorganisms $S$. aureus, $S$. pyogenes, E. coli, P. vulgaris, $P$. mirabilis, $C$. albicans were pathogenic already at $82.0 \%$ of cases.

The synergy between the presented samples of microorganisms and fungi was studied in vitro in the laboratory (Table 2).

Table 2. Symbiotic manifestations of isolated bacteria and fungi from cows with latent endometritis and salpingitis.

\begin{tabular}{|l|l|c|}
\hline \multirow{2}{*}{ Synergists } & \multicolumn{1}{|c|}{ Symbiont organisms } \\
\cline { 2 - 3 } & \multicolumn{1}{|c|}{ bacteria and fungi } & \multicolumn{1}{|c|}{ Synergy was shown, $\%$} \\
\hline E. coli & $\begin{array}{l}\text { S. aureus. S. epidermidis, S. pyogenes. } \text { P. } \\
\text { mirabilis. P. Vulgaris, C. albicans }\end{array}$ & 80 \\
\hline P. mirabilis & $\begin{array}{l}\text { S. aureus, S. epidermidis. S. Pyogenes, E. } \\
\text { coli, P. Vulgaris, C. albicans }\end{array}$ & 80 \\
\hline P. vulgaris & $\begin{array}{l}\text { S. aureus, S. epidermidis. S. Pyogenes. E. } \\
\text { coli. P. Mirabilis, C. albicans }\end{array}$ & 80 \\
\hline S. aureus & $\begin{array}{l}\text { E. coli, P. mirabilis, P. vulgaris, S. S. } \\
\text { epidermidis, S. Pyogenes, C. albicans }\end{array}$ \\
\hline S. epidermidis & $\begin{array}{l}\text { S. aureus, S. pyogenes, E. coli, P. mirabilis, } \\
\text { P. vulgaris }\end{array}$ & 70 \\
\hline S. pyogenes & $\begin{array}{l}\text { S. aureus, S. epidermidis, E. coli, P. } \\
\text { mirabilis, P. vulgaris }\end{array}$ \\
\hline C. albicans & $\begin{array}{l}\text { S. aureus, E. coli. P. mirabilis. P. vulgaris. } \\
\text { A. fumigatus }\end{array}$ & 70 \\
\hline
\end{tabular}

The analysis of the obtained data allowed to make a protocol conclusion that the phenomenon of synergy is established between the bacteria $S$. aureus, $S$. epidermidis, $S$. pyogenes, E. coli, P. mirabilis, P. Vulgaris and between fungi $C$. Albicans and $A$. fumigatus. 
Washes from the udder nipples and mammary gland skin obtained from sick cows with latent endometritis and salpingitis showed 6.2 times higher total bacterial contamination, Table 3.

Table 3. Microbiological indicators of total bacterial contamination of mammary gland and milk of sick cows

\begin{tabular}{|l|c|c|c|}
\hline Indicators & $\begin{array}{c}\text { Bacterial } \\
\text { contamination } \\
\text { of the udder } \\
\text { nipples and } \\
\text { mammary gland, } \\
\text { thousand/ } \mathrm{cm}^{3}\end{array}$ & $\begin{array}{c}\text { TAMC, milk } \\
\text { CFU/cm }\end{array}$ & $\begin{array}{c}\text { Mesophilic anaerobic } \\
\text { lactate-fermenting } \\
\text { microorganisms in } \\
\text { milk, m.c/cm }\end{array}$ \\
\hline $\begin{array}{l}\text { Latent } \\
\text { endometritis+salpingitis, } \\
(\mathrm{n}=19)\end{array}$ & $548.2 \pm 11 . \mathrm{cm}^{3} *$ & $\begin{array}{c}(5.1 \pm 0.02) \\
\mathrm{x} 10^{4 * *}\end{array}$ & $87.87 \pm 6.41^{* *}$ \\
\hline Latent endometritis, $(\mathrm{n}=8)$ & $337.4 \pm 10.35^{* *}$ & $\begin{array}{c}(4.9 \pm 0.03) \\
\mathrm{x} 10^{4 *}\end{array}$ & $92.6 \pm 7.92^{*}$ \\
\hline Salpingitis, (n=5) & $123.5 \pm 10.54^{*}$ & $(4.20 \pm 0.03) \times 10^{4}$ & $102.7 \pm 9.21^{*}$ \\
\hline $\begin{array}{l}\text { Animals without pathology, } \\
(\mathrm{n}=3)\end{array}$ & $77.3 \pm 15.4$ & $(4.02 \pm 0.07) \times 10^{4}$ & $161.6 \pm 5.52$ \\
\hline
\end{tabular}

The total bacterial contamination of washes from the surface of the udder nipples and mammary gland in cows with latent endometritis in combination with salpingitis was 478.9 \pm 22.8 thousand $/ \mathrm{cm}^{3}$, against $77.3 \pm 25.4$ thousand $/ \mathrm{cm}^{3}$ in clinically healthy lactating animals, which is 6.2 times higher $(p \leq 0.01)$, the data are statistically significant. In sick cows with latent endometritis, the contamination of the obtained samples was $387.4 \pm 12.36$ thousand $/ \mathrm{cm}^{3}$, which is 5.01 times higher $(p \leq 0.01)$ than in cows in the comparison group. Contamination of the udder nipples and the mammary gland surface of sick cows with salpingitis was $123.5 \pm 10.54$ thousand $/ \mathrm{cm}^{3}$, which is 1.6 times higher than in clinically healthy cows, the data are not statistically significant. In sick cows with latent endometritis and salpingitis TAMC, CFU/ $\mathrm{cm}^{3}$ of milk was $(5.1 \pm 0.02) \times 10^{4}, p \leq 0.05$, which is an order of magnitude higher than in clinically healthy animals - $(4.0 \pm 0.07) \times 10^{4}$. Milk obtained from cows with metritis showed 12 times higher total bacterial contamination than milk obtained from clinically healthy animals. At the same time, it has a reduced number of lactic acid organisms. The number of mesophilic anaerobic lactate-fermenting microorganisms directly dependent on the level of total bacterial contamination of the udder and of the udder nipples and mammary gland $(p<0.05)$ and on the pathogenicity of the isolated cultures of microorganisms from the genitals. (Figure 1).

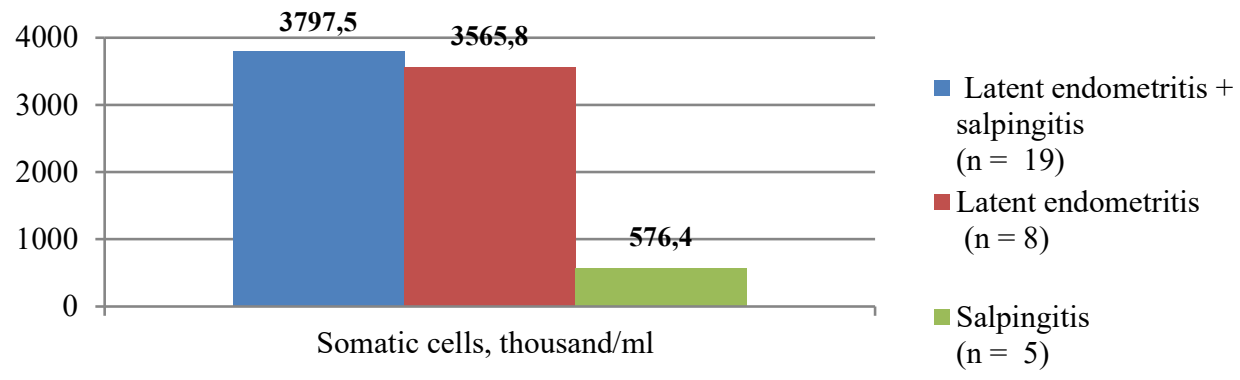

Fig. 1. Graphic representation of the indicators of the number of somatic cells in the secret of the mammary gland in cows with latent endometritis and salpingitis. 
In sick cows with latent endometritis in the udder secret, the content of somatic cells, $r=0.63$, lactoperoxidase, $r=0.65$ and lactoferin, $r=0.66$, is indicated by informative reliable indicators, with a high degree of correlation, to establish the unsuitability of milk for technological processing, Figure 2.

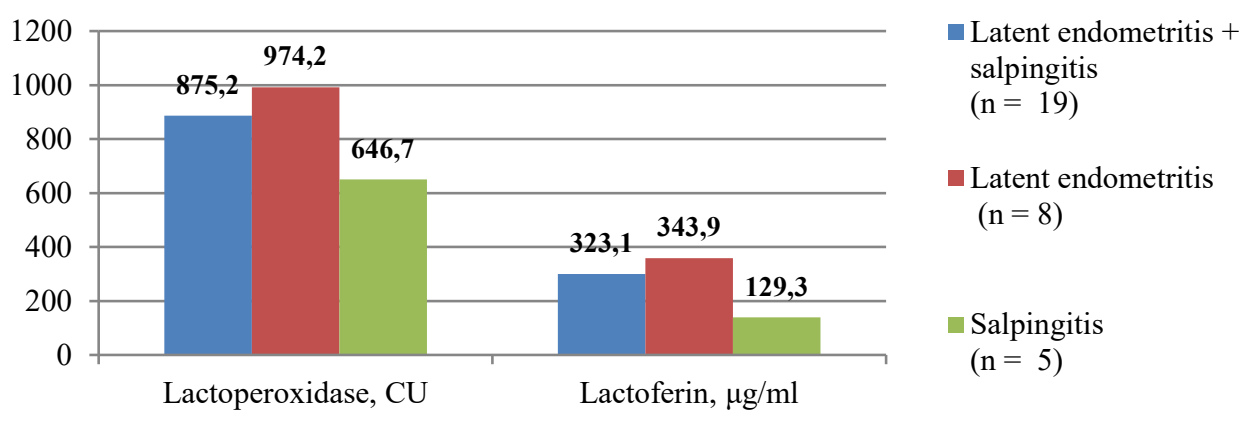

Fig. 2. Graphic representation of the indicators of lactoperoxidase and lactoferin in the secret of the mammary gland in cows with metritis.

After the conducted field studies, an experiment was organized and conducted on heifers of covering age and a body weight of 400-480 kg of the Simmental breed. 35 heifers were selected for the experiment, which were divided into 7 groups, same number of animals in each. Animals during the estrous period in the vaginal part of the cervix mouth 1 billion suspensions of various cultures of bacterial microorganisms and 150 thousand microbial cells of fungal cultures were introduced at a dose of $25 \mathrm{ml}$. The first group of experimental animals was introduced with the culture of $S$. aureus; the second - E. coli; the third - P. mirabilis; the fourth - C. albicans; the fifth - the association of cultures of $S$. aureus, E. coli, P. mirabilis; the sixth - the association of cultures of $S$. aureus, E. coli, $P$. mirabilis, C. Albicans, A. fumigatus. The animals of the seventh control group were injected with a saline solution, $25 \mathrm{ml}$. For microbiological analysis, samples were taken at intervals of two days on $3,5,7,9,11$, day from the beginning of the experiment. The results of the experiment are reflected in the data presented in Table 4.

Table 4. Incidence of the inflammatory process development in the oviducts, uterus, cervix, vagina and vulvar vestibule of heifers.

\begin{tabular}{|l|c|c|}
\hline Microorganisms & $\begin{array}{c}\text { Qty } \\
\text { of animals in the } \\
\text { experiment }\end{array}$ & $\begin{array}{c}\text { Got sick } \\
\text { With latent endometritis and } \\
\text { salpingitis, \% }\end{array}$ \\
\hline S. aureus & 5 & not found \\
\hline E. coli & 5 & not found \\
\hline P. mirabilis & 5 & not found \\
\hline C. albicans & 5 & 20.0 \\
\hline S. aureus, E. coli, P. mirabilis & 5 & 40.0 \\
\hline $\begin{array}{l}\text { S. aureus, E. coli, P. mirabilis, C. } \\
\text { albicans, A. fumigatus }\end{array}$ & 5 & 60.0 \\
\hline saline solution & 5 & not found \\
\hline
\end{tabular}

In the first, second and third experimental groups, during the experiment, no clinical signs of salpingitis, endometritis, cervicitis, vaginitis and vulvovaginitis were found in heifers. Microbiological studies have not revealed conditionally pathogenic, pathogenic microorganisms and fungi. In the fourth group, $20.0 \%$ (1) of heifers and $40.0 \%$ (2) of the fifth experimental groups a change in the behavior of heifers was observed, attention was paid to the presence of an inflammatory process in the genitals, hyperemia and spot 
hemorrhages on the mucous membranes of the external mouth of the cervix, vagina and vulvar vestibule.

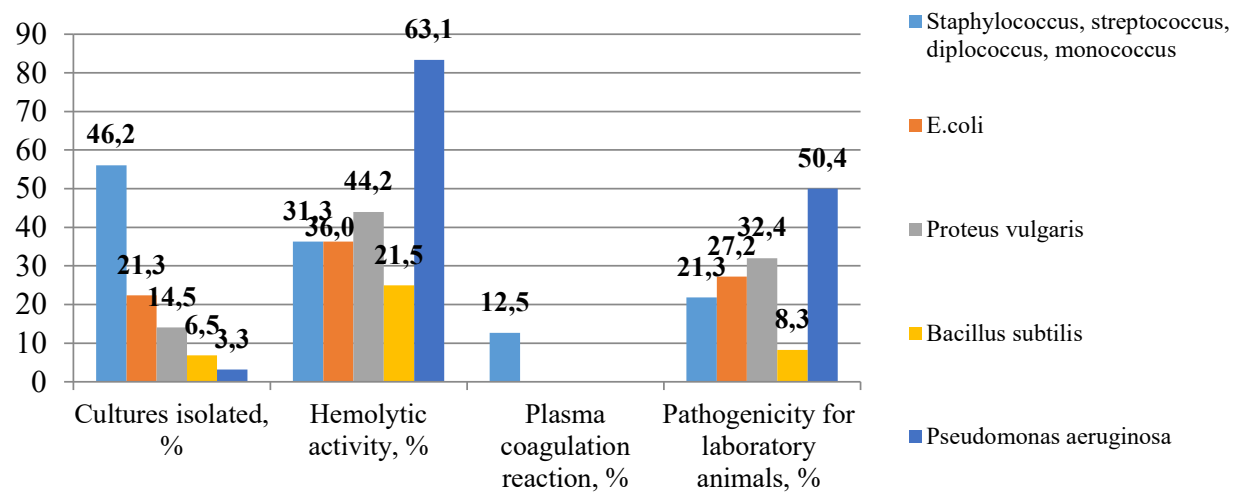

Fig. 3. Graphic image of the pathogenicity of cultures of microorganisms isolated from sick heifers during the experiment.

From a sick heifer of the fourth group, $C$. Albicans fungi were isolated, and in two heifers of the fifth group, cultures of $S$. aureus, E. coli and P. mirabilis were isolated. In bioassay version, cultures of $S$. aureus, E. coli, P. Mirabilis and C. Albicans had pathogenicity, for white mice (Figure 3). In the sixth experimental group of heifers, $60.0 \%$ (3) had salpingitis and endometritis established by sonographic and transrectal studies. In sick three heifers, hyperemia, spot hemorrhages were noted on the mucosa of vulvar vestibule, and striped hemorrhages in the vagina and on the mucosa of the external mouth of the cervix, abundant discharge with an ichorous smell, of dirty gray color. At the same time, cultures of $S$. aureus, E. coli, P. mirabilis, C. Albicans and A. Fumigatus, were isolated from sick animals, which, when setting up a bioassay, are characterized by pathogenicity for white outbreed mice. Thus, as a result of the conducted studies, microbiological studies have proved that conditionally pathogenic, pathogenic microflora are the main factor that initiates the inflammatory process on the mucous membranes of the uterine horns and oviducts $\mathrm{x}$ in $25 \ldots 50 \%$ of cases, and bacteria and fungi - in $45 \ldots 80 \%$ of cases.

\section{Conclusions}

It is established that the main pathogenesis of latent endometritis and salpingitis in highyielding cows is the microflora, which is represented by various associations of pathogenic and conditionally pathogenic microorganisms and microscopic fungi. In cows, the contents of the uterus and oviducts in $82 \%$ of cases are contaminated with various opportunistic microorganisms: E. coli $-44 \%$, S. aureus $-27 \%$, P. mirabilis $-17 \%$, K. pneumoniae $-9 \%$, $S$. pyogenes $-3 \%$. In animals with latent endometritis and salpingitis, microscopic fungi $A$. fumigatus, C. albicans, and C. crusei were isolated. Washes from the udder nipples and the mammary gland surface obtained from sick cows with latent endometritis and salpingitis showed 6.2 times higher total bacterial contamination than washes obtained from clinically healthy animals. The materials of the current work should be considered when prescribing medical procedures for animals suffering from latent endometritis and salpingitis, as an opportunity to adjust the implementation of therapeutic and preventive measures and the possibility of using the resulting milk to produce fermented milk products. 


\section{References}

1. V.D. Kocharyan, V.S. Avdeenko, G.S. Chizhova, Zh.Sh. Ushakova, Izvestiya of the Lower Volga Agrouniversity Complex: Science and higher professional education 3 (59), 308-317 (2020)

2. S.O. Loshchinin, V.S. Avdeenko, E.A. Almtaev, Veterinary medicine of farm animals 1, 33-36 (2020)

3. N.V. Rodin, G.M. Firsov, V.A. Agaltsov, V.S. Avdeenko, Zh. Scientific Life, Saratov, 15(3) (103), 434-442 (2020)

4. M. Drillich, N. Klever, W. Heuwieser, J. Dairy Sci. 90, 4275-4281 (2007)

5. H. Greven, M.P. Kowalewski, B. Hoffmann, Placenta 28, 889-897 (2007)

6. C.C. Karstrup, K. Klitgaard, T.K. Jensen, J.S. Agerholm, H.G. Pedersen , Presence of bacteria in the endometrium and placentomes of pregnant cows. Theriogenolgy, 99, 4347 (2017)

7. S.G. Moore, A.C. Ericsson, S.E. Poock, P. Melendez, M.C. Lucy, Hot topic: 16S rRNA gene sequencing reveals the microbiome of the virgin and pregnant bovine uterus. J Dairy Sci, 100, 4953-4960 (2017)

8. I. Sannmann, W. Heuwieser, J Dairy Sci, 98, 5460-5466 (2015)

9. I.M. Sheldon, G.S. Lewis, S. Le Blanc, R.O. Gilbert, Theriogenology, 65(8), 15161530 (2006) http://www.sciencedirect.com/science/article/pii/S0093691X05003821

10. I.M. Sheldon, S.E. Owens, Anim. Reprod., 14(3), 622-629 (2017)

11. Surinder S. Chauhan, Pietro Celi, Eric N. Ponnampalam, Brian J. Leury, Fan Liu and Frank R. Dunshea, Animal Production Science, 54(10), 1525-1536 (2014)

12. K. Wagener, I. Prunner, H. Pothmann, M. Drillich, M. Ehling-Schulz, Vet. Microbiol., 175, 286-293 (2015) 